\title{
Mediating Role of Co-dependency on Age and Victimisation Experiences among Indian Employees
}

\author{
Aruna Bala* and Durga Devaiah ${ }^{\dagger}$
}

\begin{abstract}
The paper examines the co-dependency of employee work and victimisation in the workplace. The mediating role of employee co-dependency is investigated through the relationship between two variables, age and workplace victimisation. The results indicate a significant positive relationship between co-dependency and victimisation. In addition, co-dependency is found to be a mediator between age and victimisation. The paper concludes by arguing that instead of dealing with workplace harassment/bullying only through legal means, a preventive intervention targeting victimisation is more effective.
\end{abstract}

Keywords Co-dependency and Victimisation, Workplace Bullying, Gendered Workplace

\section{Introduction}

Workplace bullying is pervasive around the world. A research conducted by SHRM (Society of Human Resource Management) India in 2016 highlighted that disrespect at the workplace, lack of work-life balance, over time, inability to process constructive feedback from the manager, support from manager and

\footnotetext{
* CHRIST (Deemed to be University), Bangalore, India; aruna.b@christuniversity.in

† Lowe's, India; durgadevaiah@gmail.com
} 
participation avoidance are the major causes of stress at workplace. Workplace bullying is a significant social stressor at work as well. The 2017 US Workplace bullying survey showed that almost $60 \%$ of US workers are affected by it. We can reasonably assume that this percentage is on the rise, considering the changing nature of work in the backdrop of the gig economy. Is it a worrisome trend? Studies confirm that it is increasingly becoming a matter of concern, particularly for employee well-being and organisational reputation.

Bullying is difficult to define. It is definitely not a one-off event, for which, harassment is used as a term. Bullying is an act that is intended to harm, that takes place repeatedly, and with an imbalance of power between the aggressor and target (Farrington, 1993). The present paper explores bullying from the victim's perspective. The victim is someone who is exposed to repeated negative/aggressive acts and someone who is powerless to defend their position in the situation of abuse. Victimisation is a situation in which a person perceives himself/herself to be on the receiving end of negative treatment from a person or group of people and have difficulty defending against this treatment (Matthiesen \& Einarsen, 2007).

For the majority of the cases, victims may not realise that they are getting bullied, especially in the case of subtle negative behaviours or biases. A Forbes article gives a definition by the trade union congress on bullying. It states that usually if a person genuinely feels they are being singled out for unfair treatment by a boss or colleague, they are probably being bullied (2018). The Guardian once published a series of experiences of getting bullied at the workplace, shared by the victims (2017). Those experiences range from subtle judgments, spreading rumours, verbal and emotional torture to actual threatening and coercion. Thus, the subjective perception of negative treatment varies and this creates enough complexity in deciding what constitutes it and what does not. Physical abuse (e.g. hitting, kicking or punching), verbal abuse (e.g. threatening, mocking, name-calling or spreading malicious rumours) and social isolation or exclusion in which a person is deliberately ignored (Monks et al., 2009) are the major modes of negative treatment. 


\subsection{Power Struggle in Workplace Victimisation}

Powerlessness or power imbalance can be created beyond the notion of authority. Power is the capability of an individual (A) to influence another individual (B) so that $B$ behaves by the wishes of A (Robbins \& Judge, 2007). Robbins categorised bases of power as coercive power (based on fear), reward power, legitimate power, expert power and referent power (Robbins \& Judge, 2007). Powerlessness results when there is dependence and not goal incompatibility. The targets' powerlessness has many underlying physical, psychological and legitimate causes as per Robbins and Judge's categorisation of power sources. Powerlessness can work laterally, upwardly and downwardly (Robbins \& Judge, 2007). A supervisor abusing a subordinate is an action of misusing his/her authority, and we call it downward bullying. A co-worker making use of his/her informal power (possibly referent power) for bullying can be viewed as lateral/horizontal bullying. When a subordinate misuses the expert power over his/her supervisor, it will lead to upward bullying. The recognition of upwards and horizontal bullying emphasises that there are processes beyond formal power. Personal power or power derived by a person's access to informal sources of power (e.g., expertise, information and networks of people) can be used to gain sufficient power to bully others in the workplace (Branch et al., 2013). Studies have been done in several settings such as school, workplace, cyberspace, family, romantic relationships and so on and found that power imbalance (both formal and informal) is a crucial determinant for victimisation. Victimisation is interpreted through the lens of power and dependency (Branch et al., 2013). The benefit of using power and dependency as interpretations to victimisation is that it has the potential of clarifying unusual abusive situations (subordinate abusing a supervisor, a woman misusing sexual harassment laws), which would be ambiguous otherwise.

The present study puts an effort to understand the victim and the nature of powerlessness manifested in their relationship with the abuser. The study claims that the powerlessness and dependency shown by people result in getting victimised. To characterise victims further in the angle of dependency and powerlessness, a 
concept of co-dependency is adopted from the literature on domestic violence (Rice, 2017).

\subsection{Co-dependency and Victimisation}

Co-dependency is an implicit condition for the powerlessness and dependency felt by an individual. Co-dependency is originally identified by drug and alcohol counsellors and was earlier formulated to describe those individuals who engage in relationships with substance abusers, fail to leave them even after it becomes clear that the relationship is damaging one (Frank \& Golden, 1992). The concept became popular in mental health literature towards the end of the 1970s (Anderson, 1994). Codependency is a pattern of painful dependency on compulsive behaviour and approval seeking in order to gain safety, identity and self-worth (Rice, 2017). Co-dependency results in sticking to an abusive partner and defines their identity by being associated with toxic individuals. The prefix of "co" implies shared responsibility for the abuse (Frank \& Golden, 1992).

The broad research question probed in this paper is the following: if a person is co-dependent, do they have high chances of getting victimised. The present study is anticipated to bring about strong implications concerning actual practice and academic literature. The benefit of viewing a common pattern in bullying/victimisation is that it aids in developing common theoretical frameworks to better understand and reduce the phenomenon (Monks et al., 2009). Knowing co-dependency aids people in their pursuit of selfawareness and thus drives a self-directed change within them. It empowers victims to gain control over them, which in turn, help them to live their life to the fullest. Instead of legally facing a harassment issue after it has occurred, prevention-based methods are more effective in this context. Prevention is easier if we focus on the target of harassment/ bullying than the perpetrator.

\section{Literature Review}

Pioneering research was carried out in the field of workplace bullying (Leymann, 1996). Since then, scholars were increasingly interested in systematically studying the phenomenon. Worldwide, bullying is being recognised as a serious problem within the 
working environment (SHRM, 2016). Research on the causes of workplace bullying has considered individual, work-group/social, organisational and societal explanations (Monks et al., 2009). One of the most widely known and general broad frameworks of workplace bullying was proposed by (Einarsen, 2000) wherein social, organisational and individual characteristics are presented as dynamic processes that can either obstruct or contribute to the occurrence and continuation of workplace bullying. The individual hypothesis argues that specific characteristics may predispose an individual to be a target of bullying because of their vulnerabilities in his/her disposition, or because of the provocative nature of their disposition (Matthiesen \& Einarsen, 2007). Individual characteristics may promote bullying by placing the individual in a socially exposed position; making him/her vulnerable (being unable to defend him/herself or unable to manage conflict) or causing a clash with group norms (Einarsen, 2000). Demographics have a crucial role in determining victimisation. Research on sexual harassment shows that younger women have a higher risk than older women of becoming victims of sexual harassment and same is the case with men (Gutek, 1985). Felson (1992) found that younger respondents were more likely to be both aggressors and targets of aggression.

Olweus (1994) concludes that the typical victim of bullying is more anxious and insecure than other people and is often seen as cautious, sensitive and quiet. The victim reacts with withdrawal when attacked, and they have more negative self-esteem than normal. The personality of the victim may make them easy targets of aggression and may make them vulnerable when faced with interpersonal aggression and conflicts. (Einarsen, 2000). Some studies say that victims are conscientious, liberal-minded (Brodsky, 1976). The personality profile which makes people being a target of aggression repeatedly is examined and well supported (Aquino and Thau, 2009). Research on the relationship between personality factors from the Big five reveals that victimised individuals are more conscientious and are emotionally unstable (Coyne et al., 2000). People who are low in self-esteem and those who adopt accommodative conflict management styles get bullied frequently (Bowling and Beehr, 2006). 


\subsection{Power and Dependency Perspective of Victimisation}

Einarsen (2000) highlights the power imbalance between the victim and perpetrator the core issue of abuse. A person will be victimised by exposure to repeated negative acts only if the person perceives himself to be unable to either defend himself or escape the situation. This dependency on the part of the victim may be due to social (hierarchical positions, power-relationship), physical (strength and appearance), economic (economic dependency, labour market) and psychological (victim's self-esteem, dependent personality, charismatic manager). Einarsen (2000) also states that the victims' inability to defend himself/herself may be a direct consequence of either the formal or informal power relationship between the parties, the unequal status of the parties or indirect consequences of the harassment itself.

Bullying behaviours may be in varied labels (which are observed in the number of social settings; the school, home, residential care, prisons, workplace and within a number of relationships between peers, siblings, co-workers) but what each of these generally has in common is the systematic abuse of power criterion (Branch et al., 2013). Bullying behaviours reported in romantic relationships, domestic violence, and elder abuse also has a common criterion of power imbalance (Monks et al., 2009). The assumption which is considered here is that the victims internalise a set of rules which are adaptive in abusive situations during their childhood will be recreated in workplace abuse. Smith (2004) found that those who are bullied at school are at great risk of being victimised at the workplace too.

\subsection{Theoretical Perspectives on Victimisation/Bullying}

There are two viewpoints which support perspectives on power and dependency in victimisation experience and that include; psychoanalytic approach and attachment theory

1. Psychoanalytic perspective: The power and dependency approach to victimisation have its foundations in the hypotheses of Karen Horney (2013). She recommended that a few people receive a "pushing toward" identity style to conquer their essential tension. These individuals push toward others by picking up their endorsement and 
intuitively control them through their resilient style. They are unselfish, ethical, a saint like, dependable and choose not to retaliate in spite of individual embarrassment. Endorsement from others is more important than regarding themselves. This perspective emphasises the external focus or seeking external approval is the major mode of relationship building. Victims have trouble to be assertive or say no to the perpetrator as they eagerly look for approval. Victim's need for approval makes them dependent and powerless to be assertive.

2. Attachment theory: John Bowlby (1997) first coined the term as a result of his studies involving developmental psychology of children from various backgrounds. The theory emphasises the importance of attachment in personal development by stating that the quality of attachment to parents/caregivers influences the development of an internal working model of relationships which in turn impacts on how an individual subsequently relates to others in his/her life. Ability to form an emotional and physical attachment to another person gives a sense of stability and security necessary to take risks, branch out, grow and develop as a personality (Monks et al., 2009) It explains the continuity of an insecure attachment pattern followed by the victim throughout his/her life (Monks et al., 2009).

This perspective analyses the basic foundation of the insecure attachment of victims. Inconsistent parenting instils a mentality in the victim to earn the approval of the parent or any authority figure by doing what they ask for and by being obedient.

\subsection{Co-dependency: Conceptualisation}

Melody Beattie (1987) defined co-dependency as a way of maintaining a relationship where people involved is dependent on each other to the extent that is unhealthy and toxic to them. It is a specific condition that is characterised by pre-occupation and extreme dependence (emotionally, socially and sometimes physically) on a person or object (Subby \& Friel, 1984). Codependency is essentially a state in which an individual shows extreme dependency on someone in pursuit of approval and sense 
of completion. This need creates powerlessness or perceived power imbalance which holds them back in defending their position in case of abuse. Fischer and Spann (1991) observed it as a dysfunctional pattern of relating to others with an extreme focus outside of oneself, lack of expression of feelings and personal meaning derived from relationships with others.

Rice (2017) listed a few characteristics of co-dependency; caretaking, low self-worth, depression, obsession, controlling, denial, dependency, poor communication, weak boundaries, lack of trust, anger, sexual problems and issues such as emotional, mental or physical illness. Co-dependency is hence a psychosocial condition manifested through a dysfunctional pattern of relating to others. This dysfunctional pattern of relating is characterised by extreme focus outside of self (dependency, obsession, and caretaking); lack of open expression of feelings (repressed feelings, lack of trust and poor communication) and because of low selfworth, attempts to derive a sense of purpose and meaning through relationships with others (control, denial, and rigidity). Codependency is essentially an individual's creation of dysfunctional perception about themselves, which in turn, impacts on their continued relationship with their significant others.

Schaef (1986) briefly outlined the characteristics of co-dependent people:

1. External referencing, relationship addiction, cling-clung relationships, lack of boundaries, impression management, not trusting own perceptions

2. Caretaking, making oneself indispensable, being a martyr

3. Self-centeredness, loss of morality, dishonesty

4. Control issues, gullibility, fear, rigidity, and judgmentalism

One can question the application of co-dependency (which is studied in the domestic and informal abusive situation) in a work context. In the case of abusive supervision, the perpetrator usually finds his/her partner to influence and make them work according to the wishes of the perpetrator. The person, who acts as a partner, will be someone with low self-esteem, lack of trust in oneself and need for approval on the career front. Low self-esteem, need for 
approval and so on are definite signs of the co-dependent person (Rice, 2017).

This vulnerability of victim results in a pattern of painful dependency to gain safety, identity, and self-worth, which in turn, will get misused by the perpetrator. The victim maintains a dysfunctional pattern of relating to the perpetrator with an extreme focus outside of oneself (external focus), lack of expression of feelings (being passive) and personal meaning derived from relationships with others (identity crisis) (Fischer and Spann, 1991).

The literature shows the co-dependent behaviour is associated with identity-based on caretaking and excessive responsibility for others' behaviour (Schaef, 1986). This identity is formed out of the experience of powerlessness, which is forged out as an adaptive necessity of compromise, appeasement and covert manipulation (Anderson, 1994). Historically, it has been identified as feminine malady (Fisher \& Beer, 1990), although, there are men who show excessive co-dependent behaviours. Co-dependency is found to be related to the constructs such as sex role orientation, social desirability, locus of control and self-esteem (Spann, 1989). Some of the fundamental characteristics of co-dependency such as extreme focus outside of self through dependency, obsession, and caretaking are reflected femininity dimensions of sex role orientation. Social desirability is the tendency of the people to obtain approval by responding in a culturally appropriate and acceptable manner (Crowne \& Marlowe, 1960; from Spann, 1989). This aspect of social desirability is shared with the construct of codependency, where they constantly seek approval of others. Locus of control holds that people acquire a generalised expectation about the source of reinforcement for their actions (Ashkanasy, 1985). The notion of locus of control is relevant to co-dependency in that codependent people try to have and believe they can have control over other individuals, suggesting that external forces can affect others' behaviours. Some of the characteristics of co-dependency are indicative of tendency for the external locus of control is lack of trust, low self-worth, and controlling behaviour. According to Whitley (1983), global self-esteem comprises a person's selfevaluation across several areas, such as feelings of adequacy and worth, feelings of being a good or bad person, physical appearance, 
personal skills, and sexuality. Self-esteem and co-dependency are in an inverse relationship (Spann, 1989).

\section{The Rationale of the Study}

The study empirically tests the notion that the co-dependency of a person triggers the possibilities of victimisation. Since age is found to be a determining factor in victimisation, the study attempts to incorporate age in the model. This study helps people to be aware of their co-dependency nature which act as a precipitating factor of victimisation. This encourages people to make a self-directed change within them resulting in individual empowerment. The study works as a preventive measure for bullying than a solution after the issue has happened. Basically, instead of focusing on the difficult perpetrator population, focusing on the victim (specifically, an anticipated victim of bullying) is the way to go forward.

\section{Conceptual Framework}

Based on the studies previously conducted, the conceptual framework (Figure 1) is formulated as follows

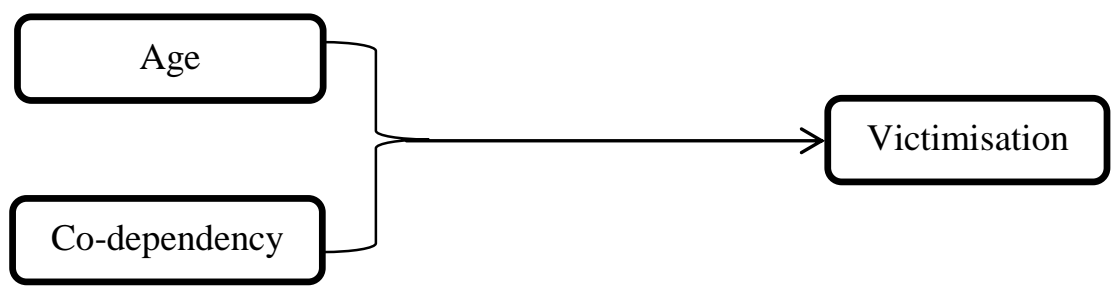

Fig 1: Conceptual Framework

The study especially focuses on the influence of co-dependency in victimisation at the workplace. The scholars have increasingly reported that young members are more victimised compared to older members of the organisation (Gutek, 1985; Felson, 1992). Higher co-dependency is associated with younger age (Lindley et al., 1999). Hence, it is reasonable to argue that co-dependency mediates the relationship between age and victimisation experience. In line with these assumptions and previous study evidence, the following hypotheses are formulated. 
1. An employee's gender is related to co-dependency and victimisation experience (Hypothesis 1a, Hypothesis 1b)

According to previous studies, women are more prone to be codependent and increasingly more reports of getting victimised (Gutek, 1985; Felson, 1992). Sociocultural theory can also be used to explain this gender difference. Stereotypes, prejudice and strong social norms against egalitarianism in the culture can result in the abuse of power imbalance.

2. Co-dependency is a mediator in the relationship between age and victimisation (Hypothesis 2)

In line with Baron and Kenny (1986), mediation requires (1) a relationship between independent variable (i.e. age and experience) and dependent variable (in this case; workplace victimisation experience), (2) a relationship between the independent variables and hypothesised mediator (co-dependency), (3) a relationship between hypothesised mediator and dependent variable (4) a decrease of the original relationship between the dependent and independent variable when taking the potential mediator into account.

H2a; Employees' age is related to workplace victimisation

H2b; Employee's age is related to co-dependency

$\mathrm{H} 2 \mathrm{c}$; Employees' age and co-dependency is related to victimisation

Hypotheses 2a, b and c tests first three stages of Baron and Kenny mediation analysis (1986). Mediation also requires a significant decrease in the relationship in the coefficient of the independent variable (employee's age), when co-dependency is added.

\section{Methodology}

Measures: Age and experience are measured in years. Codependency and victimisation are measured using a questionnaire with a five-point Likert scale. Co-dependency data was tested for Cronbach's alpha, and it showed 0.73. Spann (1989) to make a scale for co-dependency attempted to collate the literature done on the dimensions of co-dependency which demonstrates that the scholars have increasingly agreed on the dimensions of co-dependency and 
those dimensions include dependency, obsession, caretaking, repressed feelings, lack of trust, poor communication, low selfworth, control, denial and rigidity (Spann, 1989). Fischer, Spann and Crawford scale to measure Co-dependency (Fischer \& Spann, 1991) and victimisation scale (Aquino \& Bradfield, 2000) for measuring the experiences of victimisation of any kind is employed for the study. Victimisation data showed Cronbach's alpha of 0.89 .

Process of data collection: The sample was collected through online social media platforms as well as through the snowball sampling method. The sample was collected with just one rule of membership that they should be an employee of any company at present.

Sample: The study was conducted among working men (109) and women (78), making a total sample of 187 . The sample was chosen across varied sectors and age group. The idea is to recognise the prevalence of co-dependency among working people.

Method of data analysis: The study followed Baron and Kenny's method to test the mediation of co-dependency. Apart from this, the t-test is used to examine the gender differences in their victimisation experience and co-dependency behaviour.

\section{Results and Discussion}

The 187 data points were examined to explore workplace victimisation and co-dependency. A study initiated with factor analysis to investigate the underlying pattern of both the variables. Further, the impact of demographics (gender, age, and experience) was assessed. The relationship of co-dependency and victimisation was empirically evaluated employing correlation and regression analysis. The study ended with a mediation analysis to investigate the mediating role of co-dependency.

\subsection{Victimisation and the Underlying Factors}

The results of factor analysis showed that there are three factors underlying workplace victimisation; Active victimisation, passive victimisation, and job-related victimisation. 
Table 1: Descriptive of Factor Analysis: Workplace Victimisation

\begin{tabular}{lc}
\hline \multicolumn{2}{c}{ KMO and Bartlett's Test } \\
\hline Kaiser-Meyer-Olkin Measure of Sampling Adequacy. \\
Bartlett's Test of Sphericity \\
Approx. Chi-Square & 1018.848 \\
Df & 66 \\
Sig. & .000 \\
\hline
\end{tabular}

Three factors together explained $65 \%$ of the variance of workplace victimisation. Active victimisation talks about ridiculing, insulting, being shouted or yelled at and so on. Basically, victimisation happens in a profound and active form. Passive victimisation occurs in the form of spreading rumours, being singled out and allocating unimportant work and so on. Here, victims will find it difficult to realise the abuse. Job-related victimisation, although it was loaded by an only single item, is retained owing to the high magnitude of loading. The item probed was work overload. The details of the descriptive of factor analysis are given below (Table 1).

The study could not find a gender difference in the workplace victimisation; in passive, active and job-related victimisation. Finding says both men and women are equally prone to perceive victimisation at work, be it any form. The result is contradictory in the case of victimisation (Table 1). The data was scrutinised further to comprehend the reason for it and found that $50 \%$ of the sample was less than 31 years. In that, $73 \%$ were men. The present study had more men (more than 50\%) in younger age (less than 30 ). The previous researches indicated a combination of gender and age; that is, younger women report a high level of victimisation (Felson, 1992).

A correlation analysis was carried out to examine the association of workplace victimisation with age and experience. The result says that, as age and experience progresses, people tend to perceive passive victimisation less. A significant negative relationship of age, the experience of an individual with passive victimisation, is 
found. Table 2 gives the correlation table of victimisation, age, and experience of the individual.

Table 2: Age, Experience and Workplace Victimisation Correlations

\begin{tabular}{lrr}
\hline & Age (years) & Experience (years) \\
\hline Passive & $-.224^{* *}$ & $-.219^{* *}$ \\
Active & .072 & .067 \\
Job related & -.114 & -.008 \\
Age (years) & 1 & $.706^{* *}$ \\
Experience (years) & $.706^{* *}$ & 1 \\
\hline
\end{tabular}

(p value<0.001: ***; p value $<0.05:{ }^{* *} ; \mathrm{p}$ value $<0.10:^{*}$ )

\subsection{Co-dependency and Underlying Factors}

There are five themes that emerged in co-dependency; excessive caretaking, silenced self, external locus of control, guilty conscience and assertiveness. Excessive caretaking reflects prioritising others over themselves. Silenced self is about not expressing or incapable of expressing their frustration which might result in an explosion at the later stage. External locus of control indicates the tendency of people to give power to the external world to determine their happiness and decisions. Guilt conscience is a sign of high moral values or internalisation of social norms which makes them feel guilty for every socially unacceptable action. Passivity indicates the capability to say no and focus on them. The five factors together explained $59 \%$ of the variance. The details of the descriptive factor analysis are given (Table 3).

Table 3: Descriptive of Factor Analysis: Co-dependency

\begin{tabular}{lr}
\hline \multicolumn{2}{c}{ KMO and Bartlett's Test } \\
\hline Kaiser-Meyer-Olkin Measure of Sampling Adequacy. \\
Bartlett's Test of Sphericity \\
Approx. Chi-Square & .696 \\
Df & 437.083 \\
Sig. & 91 \\
\hline
\end{tabular}

Gender is examined using independent sample t-test and found that co-dependency is more evident in women samples. There is a significant difference between men and women in their codependent behaviour, specifically with reference to silenced self and passivity (Table 4). 
The silenced self reflects the difficulty accepting compliments graciously, feeling guilty for taking self-care, always prioritising significant others' needs over them, trouble for freely expressing the self- needs. This is the result of social conditioning that women tend to portray themselves as self-less and more collectivistic. Gender norms in society make them feel guilty for self-care. Similarly, passivity, which is an indication of difficulty saying NO, being vague on taking a stand and emotional irregularities are found to be more among women. Passivity is basically the lack of assertiveness. In essence, women are engaged in higher emotional labour and suppression of negative emotions compared to men, which in turn reflect in a higher level of co-dependency.

Table 4: t-test Results: Gender and Co-dependency Factors

\begin{tabular}{lr}
\hline \multicolumn{1}{c}{ Factor } & t-value \\
\hline Excessive caretaking & 0.72 \\
Silenced self & $4.39^{* *}$ \\
External focus & -1.43 \\
Guilty conscience & -0.13 \\
Passivity & $1.69^{*}$ \\
\hline
\end{tabular}

( $\mathrm{p}$ value $<0.001: * * * ; p$ value $<0.05: * * ; \mathrm{p}$ value $<0.10: *)$

The correlation results bring an interesting insight toward how codependency factors change over the years of experience and age in general (Table 5). Empirical evidence says that the age and experience of people has an inverse relationship with excessive care taking. A small significant negative relationship is found between passivity and experience of the people. As employees get more experienced, they tend to become more assertive.

Table 5: Correlation results of co-dependency factors, age, and experience of the sample

\begin{tabular}{lcc}
\hline & Age (years) & Experience (years) \\
\hline Excessive caretaking & $-.281^{* *}$ & $-.213^{* *}$ \\
Silenced self & -.142 & -.090 \\
External focus & -.137 & -.067 \\
Guilty conscience & -.019 & .042 \\
Passivity & -.087 & $-.145^{*}$ \\
Age in years & 1 & $.706^{* *}$ \\
Experience in years & $.706^{* *}$ & 1 \\
\hline
\end{tabular}

( $\mathrm{p}$ value $<0.001:{ }^{* * *} ; \mathrm{p}$ value $<0.05:{ }^{* *} ; \mathrm{p}$ value $\left.<0.10:{ }^{*}\right)$ 


\subsection{The Mediated Regression Model of Victimisation}

The study further examines the variables explaining victimisation, such as co-dependency and age. Although the data on experience at work was also collected, it was not taken for regression since age and experience has a significant positive relationship. Also, age is a factor which requires an examination when we consider the theory of attachment. Theory of attachment ascertains that childhood experiences have a long term impact on the relationships an individual makes in their lifetime. A victim will tend to get victimised if they have developed it as an internal working model for relationships. Thus, it is reasonable to believe that age will have a neutral impact on victimisation if they are co-dependent.

The present study investigates the mediation effect of codependency in the relationship between age and workplace victimisation. Mediation analysis assists in recognising the process of how age impacts workplace victimisation. The correlation result claims a significant negative relationship between age and workplace victimisation. Mediation analysis aids in understanding the 'how' part of it. The mediation analysis using the Baron and Kenny method (1986) is applied in the data and found a positive result.

Step by step results are given below

Step 1: $\quad$ Age as a factor of victimisation experience (H2a)

Step 2: $\quad$ Age and co-dependency as factors of victimisation experience $(\mathrm{H} 2 b)$

Step 3: $\quad$ Age as a factor of co-dependency (H2c)

Table 6: Mediation Analysis (Step 1 and 2)

\begin{tabular}{lcr}
\hline \multicolumn{2}{c}{ Standardised beta coefficients } \\
& \multicolumn{2}{c}{ Victimisation (Dependent Variable) } \\
\hline & $\begin{array}{c}\text { Step 1 } \\
\text { (predictors) }\end{array}$ & (predictors \& co-dependency) \\
Predictors & & -0.092 \\
Age & $-0.18^{* *}$ & $0.28^{* *}$ \\
Co-dependency & & $10.83^{* * *}$ \\
F value & $6.39 * *$ & $10 \%$ \\
Adj. $R^{2}$ & $0.03 \%$ & \\
\hline
\end{tabular}

( $\mathrm{p}$ value $<0.001: * * * ; p$ value $<0.05:{ }^{* *} ; \mathrm{p}$ value $<0.10:^{*}$ ) 
Table 7: Mediation Analysis (Step 3)

\begin{tabular}{lrr}
\hline \multicolumn{2}{c}{ Co-dependency (Dependent Variable) } \\
\hline \multicolumn{1}{c}{ Predictor } & Standardised beta coefficients \\
\hline Age & $-0.32^{* * *}$ \\
F value & $20.9^{* * *}$ \\
Adj. $R^{2}$ & $10 \%$ \\
\hline
\end{tabular}

( $\mathrm{p}$ value $<0.001: * * ; \mathrm{p}$ value $<0.05: * * ; \mathrm{p}$ value $<0.10: *$ )

The age which was significant in predicting victimisation turned out to be insignificant when co-dependency is added along with it. Adjusted $\mathrm{R}^{2}$ is also improved when co-dependency is integrated into the regression model. Thus $\mathrm{H} 2 \mathrm{a}$ and $\mathrm{H} 2 \mathrm{~b}$ are supported in the present data (Table 6). Since age predicts co-dependency, $\mathrm{H} 2 \mathrm{c}$ is also supported (Table 7).

A significant negative relationship which was shown by the variable age got insignificant when co-dependency is added as the mediator. A co-dependent person has a propensity to get victimised at any age is what is understood by the mediation analysis. Attachment theory justifies the influence of age, where you develop a pattern of internal working model, which one keeps repeating in all relationships. It also substantiates the fact that victimisation has certain common elements which are unrelated to job or situational contexts. Victimisation is more of an internal phenomenon, where co-dependency plays a major role. Previous research findings claimed the anxious and insecure profile of the victims of bullying (Olweus, 1994). The victim reacts with withdrawal and submissive when attacked, and most often their self-esteem is very abnormally low (Einarsen, 2000). Victims are also found to be responsible and liberal-minded (Brodsky, 1976) and subdued or different personality profile makes people being a target of aggression repeatedly (Aquino and Thau, 2009). Emotional instability (Coyne et al., 2000) and accommodative conflict management style (Bowling \& Beehr, 2006) is also proved among victims of bullying. In fact, when we say people are codependent, they show low self-esteem, accommodate conflict management style, sensitivity and so on. Thus, the study to some extent aligns with previous research findings. Figure 2 shows the mediated model of victimisation. 


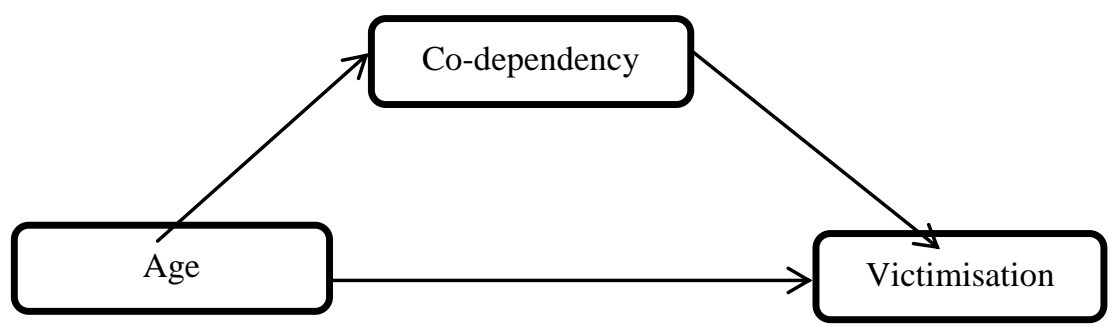

Fig 2: Mediated model of victimisation

The presence of co-dependency among victims is an explanation for their longevity in an abusive relationship (be it from supervisor or co-worker). It is not uncommon for a victim to encounter questions like why they were not reporting when the abuse occurred, why they didn't stand up against the abuse, why did they allow someone to dictate their terms and conditions on to them and so on. The present paper would like to conclude by opening the door to the possibilities of co-dependency as an explanation to those questions.

\section{Conclusion}

The study was an attempt to view victimisation through the lens of power and dependency. Using co-dependency, a concept from the literature on domestic violence, the author explored victimisation as an internal phenomenon. However, the study is not devoid of limitations. The study did not take a sample from a specific context to account for the circumstantial factors. The study can also take into consideration other factors apart from age and experience such as designation, annual income, sector, job-embeddedness to understand the phenomenon better.

There are plenty of studies that talks about the personality correlates of victimisation. The present paper adds to it by viewing it through the relationship angle. Theory of attachment and psychoanalytic perspective talks about dysfunctional relationships and its relationship to the childhood experience. Given this theoretical background, the study examined the dysfunctional relationship characterised by power imbalance and immense 
dependency, through the construct co-dependency. The study could identify the significant role of co-dependency in explaining victimisation. It opens up the possibility of understanding the nuances of a victim's behaviour before, during and after getting exposed to an abusive situation. It also assists in developing interventions for co-dependency which equip the victims to recognise and react to harassment at the right time to a certain extent.

\section{References}

Anderson, S.C. (1994). A critical analysis of the concept of co-dependency. Social Work, 39(6), 677-685.

Aquino, K. \& Bradfield, M., (2000). Perceived victimization in the workplace: The role of situational factors and victim characteristics. Organization Science, 11(5), 525-537.

Aquino, K. \& Thau, S., (2009). Workplace victimization: Aggression from the target's perspective. Annual Review of Psychology, 60, 717-741.

Ashkanasy, N.M., (1985). Rotter's internal-external scale: Confirmatory factor analysis and correlation with social desirability for alternative scale formats. Journal of Personality and Social Psychology, 48(5), p.1328.

Baron, R. M., \& Kenny, D. A. (1986). The moderator-mediator variable distinction in social psychological research: Conceptual, strategic, and statistical considerations. Journal of Personality and Social Psychology, 51(6), 1173-1182. http:// dx.doi.org/10.1037/0022-3514.51.6.1173

Beattie, M. (1987). Codependent no more: How to stop controlling others and start caring for yourself. Harper Collins: San Fransisco.

Bowling, N.A. \& Beehr, T.A. (2006). Workplace harassment from the victim's perspective: a theoretical model and meta-analysis. Journal of Applied Psychology, 91(5), 998.

Bowlby, E.J.M. (1997). Attachment: Attachment and Loss(1). Penguin Books: Australia

Branch, S., Ramsay, S. \& Barker, M. (2013). Workplace bullying, mobbing and general harassment: A review. International Journal of Management Reviews, 15(3), 280-299.

Brodsky, C. M. (1976). The harassed worker. DC Heath \& Co: Lexington

Cermak, T.L., (1986). Diagnostic criteria for co-dependency. Journal of psychoactive drugs, 18(1), 15-20.

Coyne, I., Seigne, E. \& Randall, P. (2000). Predicting workplace victim status from personality. European journal of Work and Organizational Psychology, 9(3), 335-349. 
Einarsen, S. (2000). Harassment and bullying at work: A review of the Scandinavian approach. Aggression and Violent Behavior, 5(4), 379-401.

Farrington, D.P. (1993). Understanding and preventing bullying. Crime and Justice, 17, 381-458.

Felson, R.B. (1992). "Kick'em when they're down": Explanations of the relationships between stress and interpersonal aggression and violence. The Sociological Quarterly, 33,1-16.

Fischer, J.L. and Spann, L.(1991). Measuring co-dependency. Alcoholism Treatment Quarterly, 8(1), 87-100.

Fisher, D. and Beer, J. (1990). Co-dependency and self-esteem among high school students. Psychological Reports, 66(3), 1001-1002.

Frank, P.B. and Golden, G.K., (1992). Blaming by naming: Battered women and the epidemic of co-dependence. Social Work, 37(1), 5-6.

Gutek, B.A. (1985). Sex and the workplace. San Fransisco: Jossey-Bass.

Guardian. (2017). Bullying at work week. Retrieved from https:// www. theguardian.com/ careers/series/bullying-at-work on May 14, 2019.

Here Is Why We Need To Talk About Bullying In The Work Place (Forbes) (July 29, 2018) Retrieved from https:// www.forbes.com/ sites/ pragyaagarwaleurope/2018/07/29/workplace-bullying-here-is-whywe-need-to-talk-about-bullying-in-the-work-place/

Horney, K. (2013). Neurosis and human growth: The struggle toward selfrealization. Routledge: Abingdon-on-Thames.

Leymann, H. (1996). The content and development of mobbing at work. European journal of work and organizational psychology, 5(2), 165184.

Lindley, N. R., Giordano, P. J., \& Hammer, E. D. (1999). Codependency: Predictors and psychometric issues. Journal of clinical psychology, 55(1), 59-64.

Matthiesen, S.B. and Einarsen, S. (2007). Perpetrators and targets of bullying at work: Role stress and individual differences. Violence and Victims, 22(6), 735-753.

Beattie, M. (1987). Codependent No More: How to Stop Controlling Others and Start Caring for Yourself. Harper Collins: San Fransisco.

Monks, C.P., Smith, P.K., Naylor, P., Barter, C., Ireland, J.L. and Coyne, I.(2009). Bullying in different contexts: Commonalities, differences and the role of theory. Aggression and Violent Behavior, 14(2), 146-156.

Norwood, R. (1990). Women who love too much: When you keep wishing and hoping he'll change. Pocket books: NY.

Olweus, D. (1994). Bullying at school: basic facts and effects of a school based intervention program. Journal of child psychology and psychiatry, 35(7), 1171-1190.

Rice, J.S., 2017. A disease of one's own: Psychotherapy, addiction and the emergence of co-dependency. Routledge: Abingdon-on-Thames. 
Robbins, S. and Timothy A. Judge. (2007). Organisational Behaviour. Prentice hall: New Jersey

Schaef, A.W. (1986). Co-dependence: Misunderstood- Mistreated. Harper \& Row: San Fransisco.

SHRM. (2016). Workplace stress: Impact and Outcomes [PDF File]. Retrieved from https:// www.shrm.org/ shrmindia/ Documents/ Workplace\% 20stress \% 20Impact $\% 20$ and $\%$ 20Outcomes \% 20\% 20SHRM $\% 20$ STUDY\%202016.pdfon May 14, 2019.

Smith, P.K. (2004). Bullying: recent developments. Child and Adolescent Mental Health, 9(3), 98-103.

Spann, L.A. (1989), "Developing a scale to measure co-dependency", Doctoral dissertation, University of Texas Tech Archives, Texas.

Subby, R. \& Friel, J. (1984). Co-dependency: An emerging issue. Health Communications: Pompano Beach, Florida.

Whitley, B.E. (1983). Sex role orientation and self-esteem: A critical metaanalytic review. Journal of Personality and Social Psychology, 44(4), 765.

WBI. (2017). WBI U.S. Workplace Bullying Survey[PDF File]. Retrieved from http:/workplacebullying.org/ multi/pdf/ 2017/ 2017 -WBI- USSurvey.pdf on May 14, 2019. 